\title{
Benign Ovarian Seromucinous Tumor
}

National Cancer Institute

\section{Source}

National Cancer Institute. Benign Ovarian Seromucinous Tumor. NCI Thesaurus. Code C7282.

A non-metastasizing mixed epithelial neoplasm that arises from the ovary. It is characterized by the presence of more than one epithelial cell type, most often serous and endocervical-type mucinous. This category includes seromucinous cystadenoma and seromucinous adenofibroma. 